\title{
Effect of Added Olivine on Iron Ore Agglomerate During Induration
}

\author{
Hesham Mohamed AHMED, ${ }^{1,2) *}$ Pär SEMBERG, ${ }^{3)}$ Charlotte ANDERSSON ${ }^{1)}$ and Bo BJORKMAN ${ }^{11}$ \\ 1) MiMeR Laboratory, Lulea University of Technology (LTU), Luleå, 1- SE-97187 Sweden. \\ 2) Central Metallurgical Research \& Development Institute (CMRDI), P.O. BOX 87-Helwan, Egypt. \\ 3) Luossavaara-Kiirunavara Aktiebolag (LKAB), Luleå, SE-97128 Sweden.
}

(Received on June 8, 2017; accepted on November 21, 2017; J-STAGE Advance published date: December 23, 2017)

\begin{abstract}
Olivine is used extensively in iron-pellet production as an additive in LKAB blast furnace pellets, in order to improve the high temperature properties of the finished product during reduction. As the contribution of olivine into the process depends on the available surface area, the present study was designed to find out the effect of olivine and its fineness on the oxidation-sintering and subsequent dissociation of olivine in iron ore agglomerates.

Agglomerates were exposed to different experimental conditions to study the effect of olivine on the behavior of magnetite and hematite at high temperatures. Olivine particles were found to react significantly only above $1000^{\circ} \mathrm{C}$. Porosity of the final product was found to depend largely on olivine fineness. The finer the olivine the lower the porosity of the final product. It is found also that irrespective of the starting iron oxide the ratio between hematite and spinel phase was the same after heating in air. Olivine fineness affects significantly the rate of hematite dissociation, the finer the olivine the higher the dissociation rate. Upon cooling the weight lost due to the dissociation was again regained.
\end{abstract}

KEY WORDS: iron ore pellets; induration; oxidation; sintering; olivine; fluxed pellets.

\section{Introduction}

Pellets is an important iron bearing burden material in the modern blast furnaces (BF), especially in North America and Scandinavia. ${ }^{1)}$ Important properties of pellets that should be carefully taken care of are their low temperature strength, strength after reduction, reducibility, swelling, and softening and melting behavior. The quality of pellets is influenced by the nature of the iron ore concentrate, the gangue and additives. ${ }^{2-4)}$

Sweden (LKAB, Luossavaara-Kiirunavaara AB) uses magnetite concentrates as the main feed stock for pellets production for different iron-making processes. The oxidation of magnetite into hematite is very important for the pellets induration process due to the exothermic nature of magnetite oxidation which reduces the need for external fuel. Oxidation kinetics and mechanism of magnetite pellets was reported elsewhere. ${ }^{5-10)}$ It can be summarized that oxidation of magnetite pellets is a topochemical reaction where oxygen diffuses to the reaction front through the oxidized shell. Magnetite at the center therefore remains without oxidation much longer than at the pellets surface. ${ }^{5-7)}$ Sintering of remaining non-oxidized magnetite starts at $900^{\circ} \mathrm{C}$ (magnetite starts to sinter slowly at $850^{\circ} \mathrm{C}$ while the major part of sintering occurs at $950^{\circ} \mathrm{C}$ ). On the other hand, hematite sinters at relatively higher temperatures, 900-1 $100^{\circ} \mathrm{C}$. Moreover, the presence of divalent ions such

\footnotetext{
* Corresponding author: E-mail: Hesham.ahmed@1tu.se DOI: http://dx.doi.org/10.2355/isijinternational.ISIJINT-2017-327
}

as magnesium in the magnetite lattice hinders the oxidation of some of the magnetite, as these ions are not compatible with the corundum crystal structure of hematite $\left(\mathrm{Fe}_{2} \mathrm{O}_{3}\right){ }^{6}{ }^{6}$

$\mathrm{MgO}$-rich olivine is used as an additive in LKAB blast furnace pellets to improve the high temperature properties of the finished product during reduction. ${ }^{11)}$ Its addition is known to positively affect the blast furnace performance, especially the development of the cohesive zone in the blast furnace as it narrows the softening and melting interval of the charge. ${ }^{12,13)}$ In addition, it reduces the swelling and improves pellets reducibility. ${ }^{14)}$ On the other hand, olivine addition might lead to a decrease in strength of the roasted pellets, the suggested mechanism being that olivine promotes a "duplex structure" with a heavily sintered core and less sintered shell. ${ }^{3)}$

The contribution of the added olivine to the indurated pellets during reduction was summarized earlier. ${ }^{15,16)}$ On heating, during oxidation, olivine decomposes into vitreous silica and $\mathrm{MgO}$ which later dissolves in the magnetite to form magnesioferrite or magnesiospinel. ${ }^{14)}$ The presence of $\mathrm{MgO}$ in the structure lowers the temperature at which hematite dissociates back into magnetite. Dissociation at temperatures of $1150-1200^{\circ} \mathrm{C}$ has been reported ${ }^{17)}$ and this is a couple of hundred degrees lower than the dissociation temperature of 'pure' hematite, $1392^{\circ} \mathrm{C}$ in air. ${ }^{18)}$

The present study aims at evaluating the effect of olivine and its particle size on the oxidation and sintering of olivine containing magnetite iron ore concentrate agglomerates. The agglomerates were investigated by means of thermogravimetry under different conditions. Swelling and sinter- 
ing of the agglomerates during induration was monitored using an optical dilatometer under oxidizing atmosphere (air). Microstructure and phase distribution were carefully examined using SEM-EDS. The effect of olivine fineness on dissociation of hematite into spinel phase was studied by thermogravimetry together with thermodynamic calculations (FactSage).

\section{Experimental}

Iron ore concentrate was collected from LKAB (Luossavaara-Kiirunavaara AB, Sweden) Malmberget. This study was done with olivine form Åheim in Norway. The Åheim olivine if magnesium-rich forsteritic type. Bentonite was used a binder. Typical Chemical analysis of the used materials is given in Table $\mathbf{1}$.

Two different shapes of sample were used in the present study. First set of samples were produced by mixing magnetite and hematite concentrates with $10 \%$ olivine, respectively. The mixtures were then pressed by a hydraulic press with a pressure of $1.5 \mathrm{KN}$ into briquettes. These samples were used only to figure out the behavior of olivine in magnetite and hematite matrixes at different temperatures and oxygen pressures. The second set of samples was olivine containing magnetite concentrate pellets which were produced by agglomerating finely ground magnetite concentrate and olivine, moist together with a binder $(9.2 \%$ moisture and $0.5 \%$ bentonite) in balling discs to pellets (9-15 $\mathrm{mm}$ diameter), the pelletizing method was described in detail earlier. ${ }^{19)}$ Four different types of pellets were prepared at LKAB micro-balling laboratory. One type of these pellets was made with no added olivine while the other three were made by adding three different particle sizes of olivine (20-38, 53-75, 106-150 $\mu \mathrm{m}$ and will be named as olivine 1,2 and 3 respectively). $3 \%$ Olivine addition was fixed. All calculations are based on dry ore weight.

Seven dried pellets of each type were used for induration (isothermal oxidation-sintering) experiments utilizing a tubular furnace with an alumina tube inside. Detailed description of the experimental setup and schematic diagram showing the furnace assembly are given elsewhere. ${ }^{14)}$ The induration experiments were started by heating the furnace to a predetermined temperature $\left(800,1000\right.$, and $\left.1250^{\circ} \mathrm{C}\right)$. After the furnace temperature stabilized and while flushing the furnace with preheated oxidizing gas (air), dry samples were lowered to the even temperature zone of the furnace and kept for 20 minutes. After 20 minutes, the samples were quenched by removing them from the hot zone and placed in a cold stream of air. The samples were then weighed and kept for further analysis. Oxidation degree of the quenched samples was quantified based on manual weighing of the samples before and after experiment.

Porosity of the quenched samples as a function of temperature as well as olivine particle size were calculated based

Table 1. Mineralogical composition of the used raw materials.

\begin{tabular}{crrrrc}
\hline Minerals & \multicolumn{1}{c}{$\mathrm{Fe}$} & $\mathrm{SiO}_{2}$ & $\mathrm{MgO}$ & $\mathrm{CaO}$ & $\sum \mathrm{Na}_{2} \mathrm{O}+\mathrm{K}_{2} \mathrm{O}$ \\
\hline Iron ore concentrate & 70.88 & 0.71 & 0.20 & 0.13 & 0.10 \\
Olivine & 5.63 & 41.72 & 48.25 & 0.32 & 0.10 \\
Bentonite & 3.63 & 51.64 & 0.68 & 6.43 & 3.30 \\
\hline
\end{tabular}

on bulk and true density measurements. Micrometrics pycnometer 1305 was used to measure the pellets true density utilizing a $35 \mathrm{~cm}^{3}$ cell. The bulk density was measured by means of manual determination of average pellet diameter and weight. The pellets microstructure was investigated using Zeiss Germin Merlin Scanning Electron Microscopy (SEM) coupled with energy dispersive spectroscopy (EDS). Three selected pellets from each run were cut in two parts with thin diamond saw and then mounted in an epoxy resin and polished down to $1 / 4 \mu \mathrm{m}$ fineness with diamond paste. Prior to SEM imagining, all samples were optically checked using Canon optical microscope.

Moreover, the effect of olivine particle size on swelling and sintering was investigated visually by observing the change of sample size as a function of time and temperature. Leitz Wetzlar Germany optical dilatometer was used for this purpose. Detailed description of the used instrument is given an earlier publication. ${ }^{20)}$ Gently ground pellets were agglomerated into small briquettes $(3 \mathrm{~mm}$ height and $2 \mathrm{~mm}$ diameter) using a specially designed mold. The briquette was then centered on a flat alumina pan and then introduced to the hot zone of a horizontal tube furnace. The two endings of the furnace are closed with transparent quartz stoppers to enable atmosphere control and imaging. Air gas flow was maintained throughout the process. The sample was heated $15^{\circ} \mathrm{C} / \mathrm{min}$ up to $600^{\circ} \mathrm{C}$ and $10^{\circ} \mathrm{C} / \mathrm{min}$ up to $1300^{\circ} \mathrm{C}$ and then kept $20 \mathrm{~min}$ at the final temperature. Imaging was set to carry out automatically according to preset parameters (every $10^{\circ} \mathrm{C}$ or when the volume changes by $1 \%$ ). The change of sample size was monitored by analysis of the sample silhouette and was calculated accordingly.

A Netzsch STA 409 thermo-gravimetric analyzer ${ }^{20)}$ with sensitivity $\pm 1 \mu$ g (TGA) was used to evaluate and analyze the effect of olivine particle size on the process kinetics. Two different sets of experiments were conducted. In both sets, the sample was positioned on a pan-like crucible in the hot zone of the furnace. A controlled gas flow rate was maintained through all the experiments. The design of the crucible ensures easy oxygen access to the sample. The samples were heated according to a predetermined thermal profile. The reaction progress was monitored by recording the mass change as a function of time and temperature. The samples were then left to cool in the furnace and kept for further analysis.

\section{Results}

\subsection{Induration Experiments}

Interrupted experiments were utilized to quantify the effect of olivine existence and its particle size as well as temperature on oxidation and sintering. Table 2 and Fig. 1 show the oxidation degree and porosity as a function of temperature for olivine and olivine-free magnetite pellets. Oxidation degree $(\alpha)$ was calculated based on the equation below;

$$
\alpha=\left[\frac{w_{t}-w_{i}}{w_{T}}\right] * 100
$$

Where, $w_{t}$ is the instant weight, $w_{i}$ is the initial weight and $w_{T}$ is the theoretical mass gain which can be calculated based on Eq. (2) 


$$
w_{T}=\left[\left(\frac{3\left(M_{\mathrm{Fe}_{2} \mathrm{O}_{3}}\right)-2\left(M_{\mathrm{Fe}_{3} \mathrm{O}_{4}}\right)}{2\left(M_{\mathrm{Fe}_{3} \mathrm{O}_{4}}\right)}\right) * m_{\mathrm{Fe}_{3} \mathrm{O}_{4}} \%\right]-0.22 \ldots
$$

$\mathrm{M}_{\mathrm{Fe}_{2} \mathrm{O}_{3}}$ and $\mathrm{M}_{\mathrm{Fe}_{3} \mathrm{O}_{4}}$ stand for molecular weight of hematite and magnetite, respectively, while $m_{\mathrm{Fe}_{3} \mathrm{O}_{4}} \%$ stands for the mass percentage of magnetite. The value 0.22 is corresponding to the weight loss percentage that happen due to calcination and dehydration of binding materials.

As expected, the oxidation degree increases as the temperature rises up to $1000^{\circ} \mathrm{C}$ while above $1000^{\circ} \mathrm{C}$ the oxidation degree increase is negligible, irrespective of the olivine existence and its fineness. No clear trend could be drawn for the effect of olivine existence and its fineness on oxidation degree under the present experimental conditions.

The measured true and bulk densities for indurated pellets were used to calculate the corresponding porosities as shown in Fig. 1. Olivine free pellets show a slight decrease in porosity as the temperature increases while for olivine containing pellets the porosity increases in the beginning, as the temperature increases up to $1000^{\circ} \mathrm{C}$, and then decreases as the temperature rise up to $1250^{\circ} \mathrm{C}$. Porosity measurements show that at $1250^{\circ} \mathrm{C}$ olivine free pellet has the highest porosity $(26 \%)$ while the finest olivine containing pellets exhibit the lowest porosity $(19 \%)$. The difference in the final product porosities can be attributed to the enhanced sintering due to the presence of magnesioferrite or the increased slag formation.

\subsection{Optical Dilatometer}

Induration of magnetite briquettes was examined visually by a continuous $2 \mathrm{D}$ imaging using an optical dilatometer.

Table 2. Oxidation degree of indurated pellets at different temperatures for $20 \mathrm{~min}$.

\begin{tabular}{cccc}
\hline & \multicolumn{3}{c}{ Oxidation degree $(\%)$} \\
\cline { 2 - 4 } & $800^{\circ} \mathrm{C}$ & $1000^{\circ} \mathrm{C}$ & $1250^{\circ} \mathrm{C}$ \\
\hline Olivine free & 83 & 91 & 93 \\
Olivine 1 $(20-38 \mu \mathrm{m})$ & 80 & 91 & 90 \\
Olivine 2 $(53-75 \mu \mathrm{m})$ & 81 & 92 & 93 \\
Olivine 3 $(106-150 \mu \mathrm{m})$ & 80 & 93 & 93 \\
\hline
\end{tabular}

Irrespective of olivine existence and its particle size, a linear expansion was detected as the temperature rises from room temperature to $1100^{\circ} \mathrm{C}$ followed by shrinkage at higher temperature (Fig. 2). The similarity of sintering behavior can be attributed to the homogenous oxidation through the whole briquette which is enabled by the slow heating rate and the ease access of oxygen to the heated briquette. Further, as soon the temperature reaches $1300^{\circ} \mathrm{C}$, olivine containing briquettes showed break points where the samples manifested limited expansion followed by shrinking. The limited expansion is due to the lattice expansion which results from dissociation of hematite back to magnetite. The break points (because of hematite dissociation) become less pronounced as the olivine particle sizes become coarser. In olivine free briquettes, the break point (hematite dissociation) delayed about $10 \mathrm{~min}$ which is in an excellent agreement with the fact that olivine free hematite briquettes offer higher thermal stability due to the limited availability of magnesioferrite or the spinel phase. The continuation of shrinkage after dissociation until the end of the heating cycle is due to sintering.

\subsection{Microstructural Examination}

Low and high temperature oxidation mechanism was explained in detail by Niiniskorpi and Forsmo. ${ }^{21-23)}$ The change of olivine structure during oxidation and reduction of magnetite concentrate containing pellets were studied in the present laboratory by Semberg et al., ${ }^{24)}$ and Leimalm et $a l .{ }^{25)}$ The present investigation showed that olivine particles manifest no change during pellets induration up to $1000^{\circ} \mathrm{C}$ irrespective of its particle size (Figs. 3(a)-3(c)). Significant change was observed only in pellets indurated at $1250^{\circ} \mathrm{C}$ (Figs. 3(d)-3(f)). At $1250^{\circ} \mathrm{C}$ fine olivine particles (20-38 $\mu \mathrm{m})$ have reacted completely and in most cases the entire particle has the structure of the second corona as shown in Fig. 3(d) (magnesioferrite crystals in a matrix of silica). On the other hand, the change appears to be limited in bigger particles $(106-150 \mu \mathrm{m})$. Both SEM and LOM images shows an increase in spinel phase surrounding the olivine particle with a decreasing olivine particle size. Microscopic structure and chemical analysis of reacted olivine particle is depicted

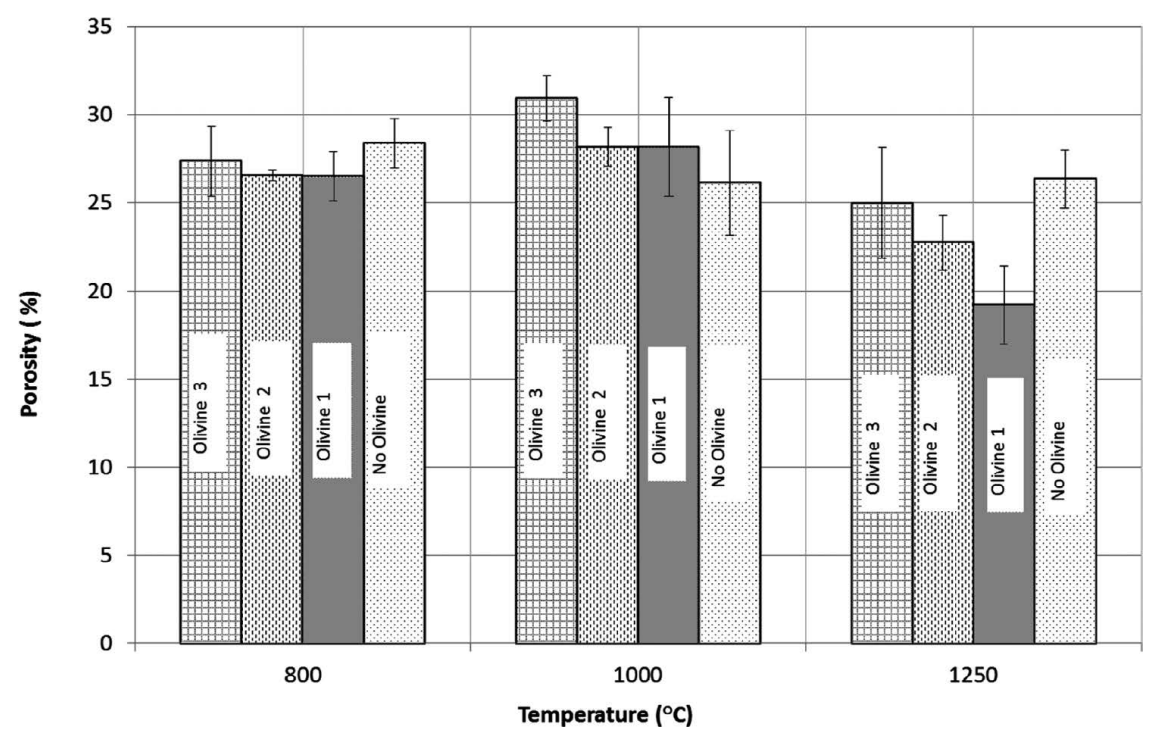

Fig. 1. Calculated porosity values for different types of magnetite concentrate pellets as a function of temperature. 


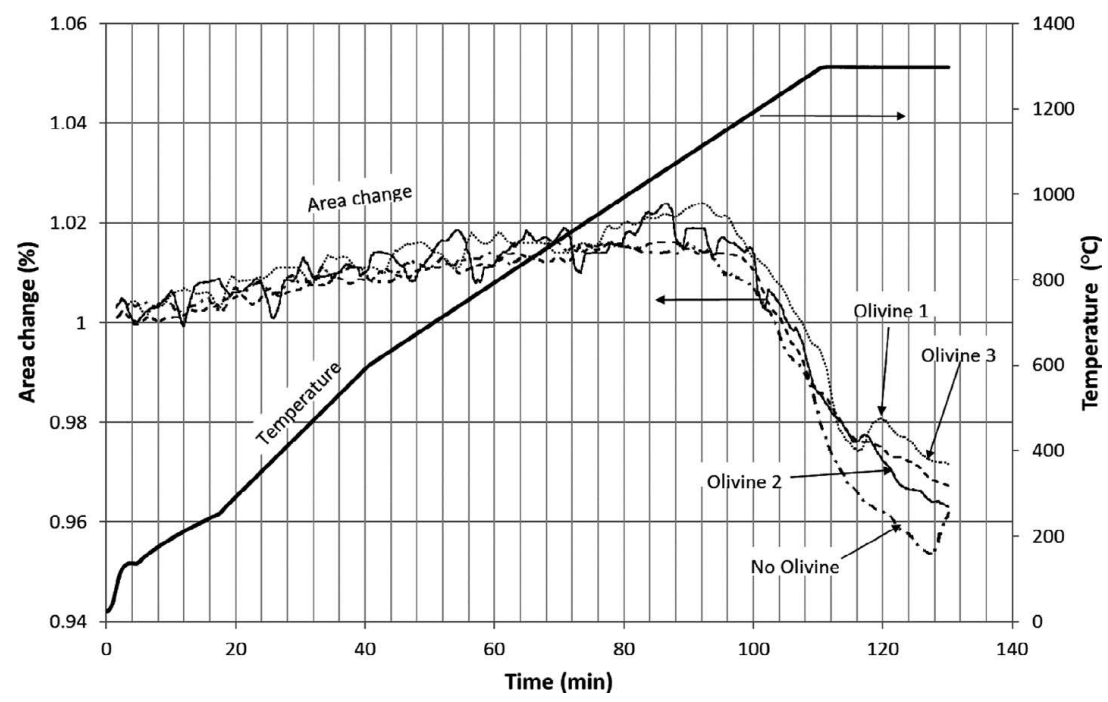

Fig. 2. Samples silhouette area change as a function of time and temperature.

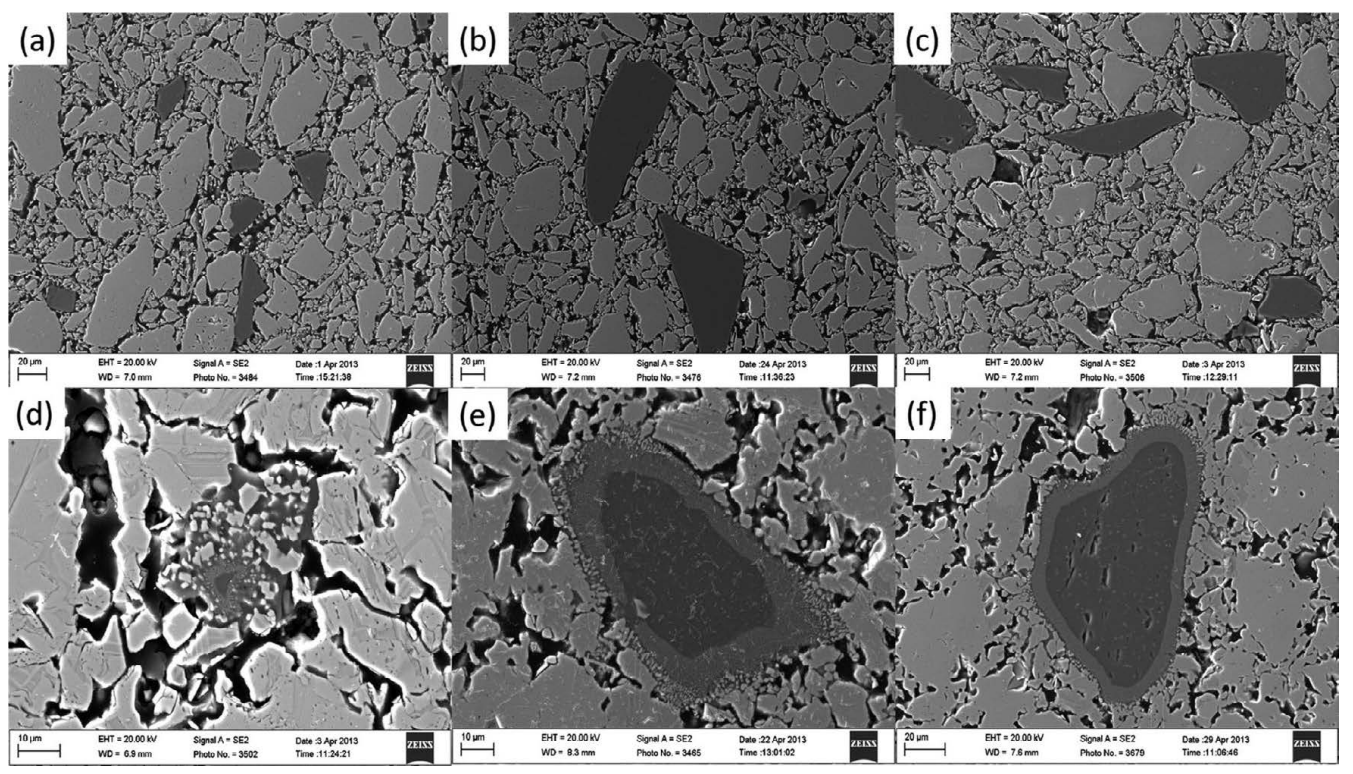

Fig. 3. SEM images of quenched pellets after induration under air for $20 \mathrm{~min}$ at $1000^{\circ} \mathrm{C}$ a) Olivine 1, b) Olivine 2, c) Olivine 3 and at $1250^{\circ} \mathrm{C}$ d) Olivine 1, e) Olivine 2 and f) Olivine 3.

in Fig. 4. It shows a typical reacted olivine particle and its coronas (reaction zones) structure and the corresponding elemental composition for each corona. The obtained elemental analysis is in a good agreement with the reported scenario for olivine reactions. ${ }^{24)}$

\subsection{Thermogravimetric Results}

Magnetite oxidation can be represented by Eq. (3). Magnetite pellets $\left(100 \% \mathrm{Fe}_{3} \mathrm{O}_{4}\right)$ are theoretically expected to face weight gain up to $3.455 \%$ on heating under oxidizing atmosphere due to formation of hematite. Weight loss of $0.22 \%$ due to calcination and dehydration of binding materials is expected. Bentonite contains up to $10 \%$ free water and about $10 \%$ structurally bound water which is lost in the temperature range $500-800^{\circ} \mathrm{C}$. The oxidation degree $(\alpha)$ was calculated based on Eqs. (1) \& (2). This leads to calculated mass gain of $3.17 \%$ for a sample of $70.88 \% \mathrm{Fe}$ with addition of $0.5 \%$ bentonite, and $3.12 \%$ for a sample containing $0.5 \%$ bentonite $+3 \%$ olivine.

$$
4 \mathrm{FeO} \cdot \mathrm{Fe}_{2} \mathrm{O}_{3}+\mathrm{O}_{2}=6 \mathrm{Fe}_{2} \mathrm{O}_{3}
$$

\begin{tabular}{|c|c|c|c|c|c|}
\hline & $\begin{array}{l}\text { ical elemental dist } \\
\text { ine particle and its }\end{array}$ & $\begin{array}{l}\text { ributic } \\
\text { surrol }\end{array}$ & & & \\
\hline No. & Position/element & $\mathrm{Mg}$ & $\mathrm{Si}$ & $\mathrm{Fe}$ & $\mathrm{Ca}$ \\
\hline & Dark core & 28 & 17 & 4 & -- \\
\hline II & $1^{\text {st corona }}$ & 15 & 17 & 17 & 1 \\
\hline III & $2^{\text {nd }}$ corona & 3 & 20 & 30 & -- \\
\hline IV & Surr_1 & 6 & -. & 57 & -- \\
\hline V & Surr_2 & -- & 1 & 63 & -.- \\
\hline
\end{tabular}

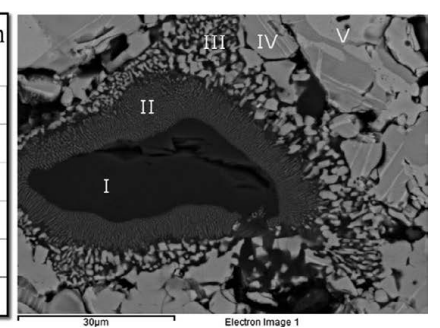

Fig. 4. SEM image and elemental analysis of typical olivine particle. Where; I) dark core, II) 1st corona, III) 2nd corona, IV) surrounding 1 and V) surrounding 2.

Figure 5 shows the results from the first set of thermogravimetric experiments on hematite and magnetite briquettes. Samples were heated in inert atmosphere (argon) until temperature approached the predetermined isothermal temperature. Isothermal tests were carried out in a constant flow rate of air $(200 \mathrm{ml} / \mathrm{min})$ with hematite and magnetite briquettes, at three different temperatures, 1 100, 1200 and $1270^{\circ} \mathrm{C}$. The results show that the hematite briquettes start to lose weight at $\sim 1130^{\circ} \mathrm{C}$ during heating, the higher is 
the indurating temperature the higher the weight loss. The magnetite samples start to oxidize and gain weight as soon as the inert gas is replaced by air. The weight gain decreases with increasing temperature. The relative weight difference between the samples at different temperatures resembles that between the hematite samples. For both hematite and magnetite, an immediate weight gain occurs upon replacement of inert gas by air, and a similar weight loss occur when the air is again exchanged for inert gas at the end of the isothermal period.

Figures 6 and 7 show the results from the second set of thermogravimetric experiments. Magnetite pellets containing olivine of three different finesses were oxidized in air $(600 \mathrm{ml} / \mathrm{min})$ under a program including both heating, an isothermal portion and cooling segments. The sample begin to gain weight at around $350^{\circ} \mathrm{C}$ and appear to reach steady state at about $960^{\circ} \mathrm{C}$, at a level of $\sim 3.1 \%$ mass gain. The TGA curves show that all samples behave similarly until $\sim 1200^{\circ} \mathrm{C}$ where a sudden weight loss occurs. The finer is the olivine particles in the pellets the higher the weight loss. Upon cooling the samples again gain weight to reach an oxidation degree even slightly higher than during the steady state period. The magnified portion of the TG-curves (see Fig. 7), shows the difference in weight gain between the samples. The blue lines in the figure represent theoretical

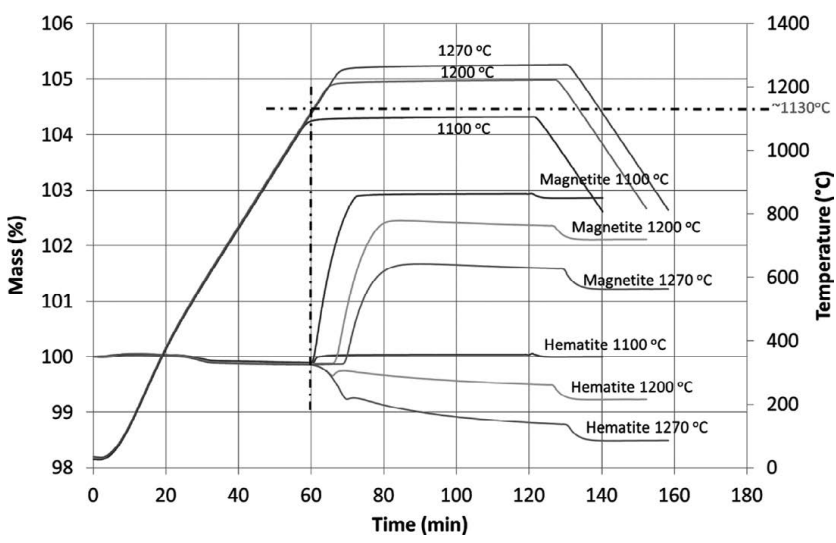

Fig. 5. Isothermal treatment in a $200 \mathrm{ml} / \mathrm{min}$ airflow at 1100 , 1200 and $1270^{\circ} \mathrm{C}$ of magnetite and hematite briquettes containing $10 \%$ olivine. oxidation of the samples which corresponds to $3.17 \%$ mass gain for the olivine-free sample (line 1) and 3.12\% for the samples with olivine if no interaction olivine-iron oxide is assumed (line 2). Lines marked with 3 show that the oxidation degree during the cooling segment reaches a level even higher than the initial oxidation. Line 4 clarify that the dissociation starts slightly before the isothermal segment. Line 5 point out the maximum observed mass loss due to dissociation of hematite.

\section{Discussion}

The weight loss observed in these studies is associated with the hematite phase becoming unstable at higher temperatures. Figures 8 and 9 show the phase diagram $\mathrm{Fe}_{2} \mathrm{O}_{3}-$ $\mathrm{MgO}$ and the change of $\mathrm{FeO}$ content in samples containing 0-10\% MgO upon heating, calculated by FactSage. ${ }^{26)}$ Factsage calculations revealed that, thermodynamically, pure hematite remains hematite until $1376^{\circ} \mathrm{C}$ where all hematite dissociates into magnetite spinel. If $\mathrm{MgO}$ is present, a certain amount of $\mathrm{MgO}$-containing spinel phase coexists with the hematite all the way until reaching the temperature for the one-phase spinel stability region of the diagram, see Fig. 8. When approaching this temperature, more and more of the remaining hematite transfers (dissociates) into the magnetite spinel with a low content of $\mathrm{MgO}$. The more $\mathrm{MgO}$ in

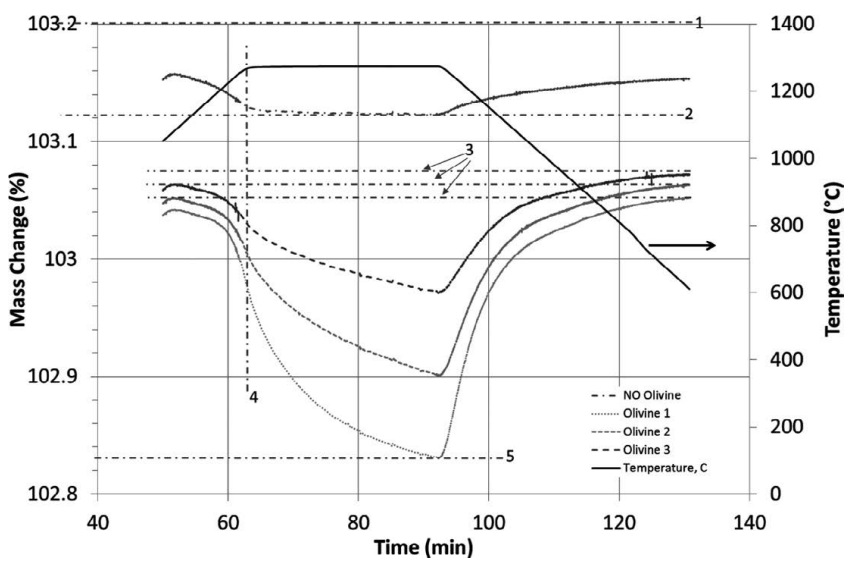

Fig. 7. Magnification of the high temperature portion of Fig. 6.

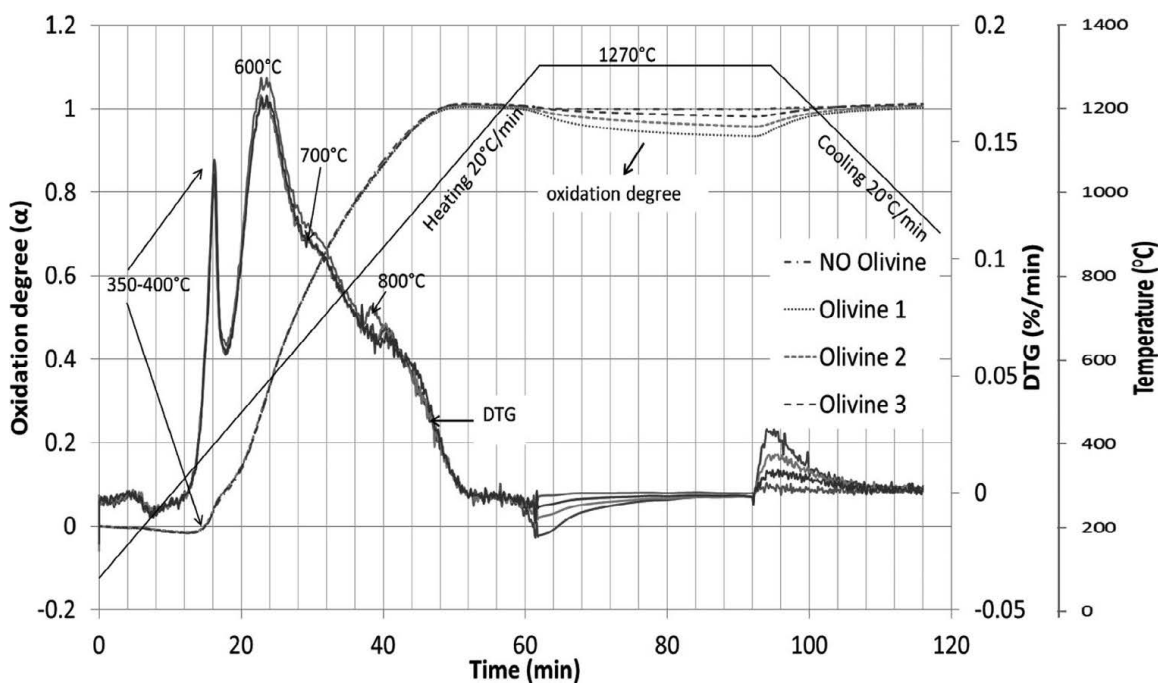

Fig. 6. Non-isothermal oxidation of olivine free and olivine containing magnetite pellets. 
the samples, the earlier is the conversion of the last hematite into the $\mathrm{MgO}$ containing spinel, since the hexagonal hematite can host only negligible amounts of $\mathrm{MgO}$. The involved reaction could be simplified by Eq. (4)

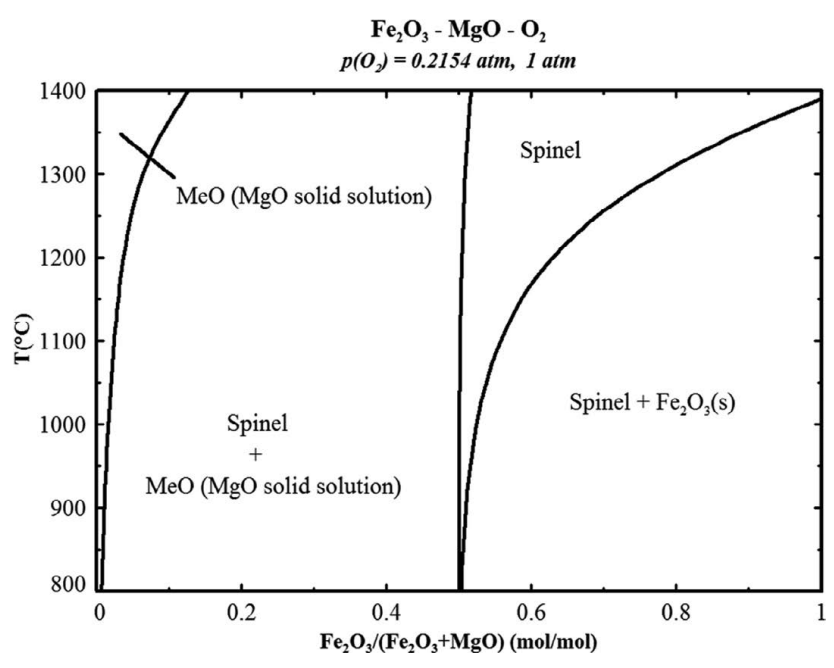

Fig. 8. Phase diagram $\mathrm{MgO}-\mathrm{Fe}_{2} \mathrm{O}_{3}$ calculated by FactSage.

$$
\begin{aligned}
& 2 \mathrm{Fe}_{3} \mathrm{O}_{4}+3(\mathrm{Mg}, \mathrm{Fe}) \mathrm{SiO}_{3}+1 / 2 \mathrm{O}_{2} \\
& \leftrightarrow 3(\mathrm{Mg}, \mathrm{Fe}) \mathrm{Fe}_{2} \mathrm{O}_{4}+3 \mathrm{SiO}_{2}
\end{aligned}
$$

In Fig. 10 the TG-curves for hematite samples in Fig. 5 have been relocated and fitted with the curves of the magnetite which is being oxidized to hematite. It is clear that the amount of weight loss of the hematite briquettes corresponds to the loss of oxidation degree for the oxidized magnetite briquettes. The oxidation state of the sample hence approaches the same equilibrium regardless whether the initial composition is magnetite or hematite. Upon oxidation, the $\mathrm{MgO}$ (from the olivine) in the magnetite sample hinders part of the magnetite spinel phase from transforming into hematite. The hematite samples show a similar behavior by dissociating (as $\mathrm{MgO}$ lowers its dissociation temperature) so that the final composition obtained between hematite and magnetite spinel is about the same as in the oxidized magnetite samples. Significant dissociation starts before the isothermal period, with the commence of the dissociation occurring at around $1130^{\circ} \mathrm{C}$ in argon. From the experiments, the replacement of inert gas with air has a relatively small impact on the weight

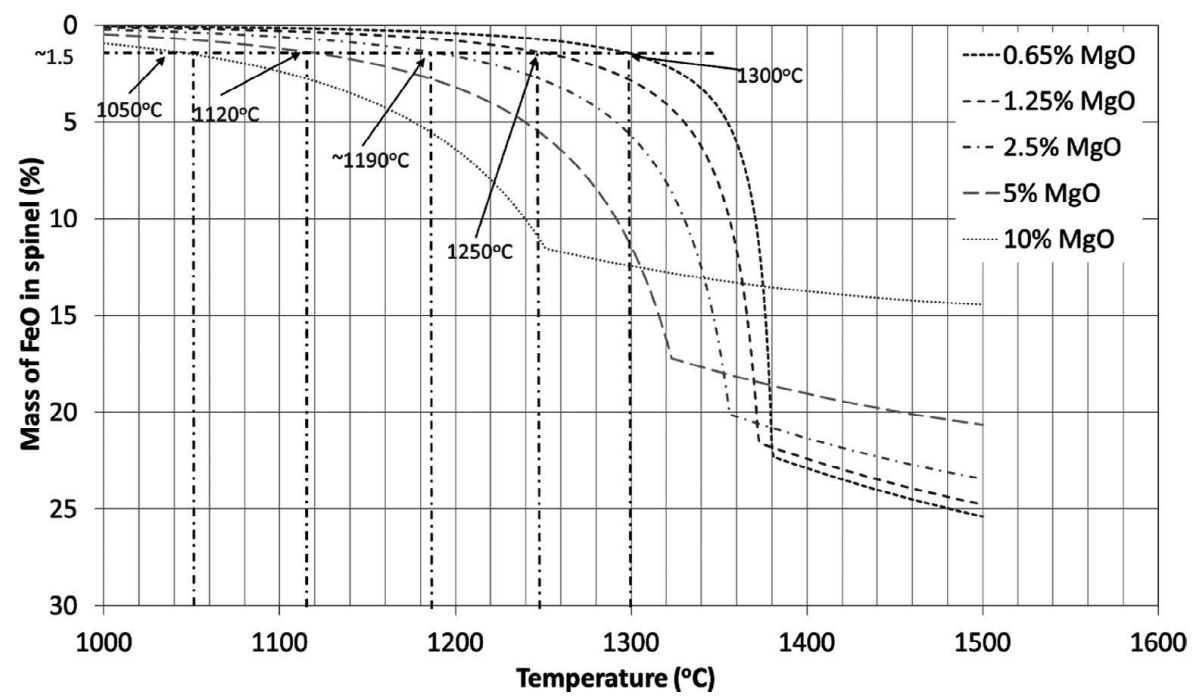

Fig. 9. Increase of $\mathrm{FeO}$ upon heating in hematite samples containing 1.25, 2.5, 5 and $10 \mathrm{wt}-\% \mathrm{MgO}$ due to dissociation of hematite. The data is based on thermodynamic calculations.

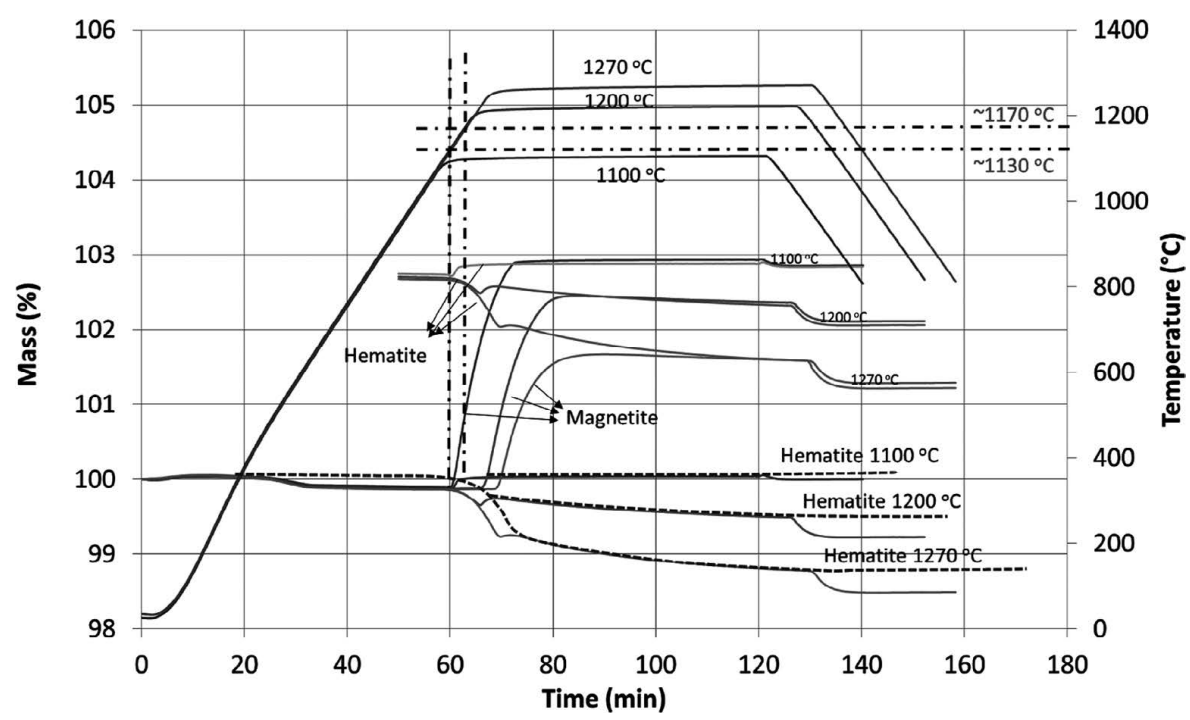

Fig. 10. TG-curves of Fig. 9 mounted to show how magnetite and hematite approaches the same equilibrium. 
curves. It is possible to draw up estimated curves for the behavior if the gas would have remained the same, inert or air, throughout the experiments. The dashed line in Fig. 10 shows the estimated dissociation curve for hematite if the gas would have kept air from the beginning. The dissociation starts a little later than in argon, at around $1170^{\circ} \mathrm{C}$.

If thermodynamics is governing the dissociation of hematite, then the pellets in Fig. 6 should have their main weight loss at a higher temperature than the briquettes in Fig. 5, due to the lower $\mathrm{MgO}$-content. Figure 9 suggests a temperature of about $1250^{\circ} \mathrm{C}$ for a sample with $1.25 \% \mathrm{MgO}$, and around $1120^{\circ} \mathrm{C}$ for a sample with $5 \% \mathrm{MgO}$. However, the relative difference between the different $\mathrm{MgO}$-concentrations remains. Figure 7 shows that the temperature range for the rapid weight loss for the three different samples is $1190-1230^{\circ} \mathrm{C}$ which is just a little higher than the temperature observed for the briquettes with the higher amount of $\mathrm{MgO}$ in Fig. $10,1170^{\circ} \mathrm{C}$. This is similar to a previous work where dissociation started at $1180-1205^{\circ} \mathrm{C}$ for different finesses of added olivine, in an experiment in air at heating rate $5^{\circ} \mathrm{C} / \mathrm{min}$. With no olivine in the sample, the dissociation started at $\sim 1280^{\circ} \mathrm{C}$. .)

In Fig. 7 the dissociation continues even during the full time of the isothermal portion ( $25 \mathrm{~min}$ ), which shows that the system does require a bit of time to settle at equilibrium at these temperatures. Sufficient time was not available to attain equilibrium in the current experiments with a heating rate of $20^{\circ} \mathrm{C} / \mathrm{min}$. Upon cooling the whole mass loss is regained which indicates that no significant amounts of additional $\mathrm{MgO}$ was released from the olivine particles during the $\sim 1 \mathrm{~h}$ which passed since the commence of the weight loss. The same rate of temperature change, $20^{\circ} \mathrm{C} / \mathrm{min}$, was used for the cooling as for the heating, which implies that the final amount of spinel in the sample in Fig. 7 is to be related to the point when temperature made diffusion too slow, and not necessarily to the equilibrium level. In the figure, the weight is still slightly at move at $600^{\circ} \mathrm{C}$ when data logging was stopped. In equilibrium experiments, it was considered not possible to produce equilibrium data under $500^{\circ} \mathrm{C}$ due to slow diffusion rate. ${ }^{27)}$

\section{Conclusions}

Effect of olivine fineness on oxidation and sintering of iron ore and subsequent dissociation was investigated. The following conclusion can be drawn;

- Olivine starts to react significantly after $1000^{\circ} \mathrm{C}$ which is indicated by formation of reaction coronas. At $1250^{\circ} \mathrm{C}$ fine olivine particles react completely whereas reaction is limited for larger olivine particles.

- Porosity of the final product was found to vary depending on olivine fineness. During oxidation, porosity increase slightly until $1100-1150^{\circ} \mathrm{C}$ after which the sample shrinks with reduced porosity. The finer the olivine, the lower the porosity of the final product.

- Upon treatment in air, the same ratio between hematite and spinel is obtained regardless weather the initial iron oxide is magnetite or hematite.

- Dissociation of already formed hematite in a $\mathrm{MgO}$ containing system thermodynamically occur upon heating already from $1000^{\circ} \mathrm{C}$, with mass loss following exponential curves. Increased level of dissociation occurs with rising of the temperature until reaching the temperature for the spinel-one phase region where hematite cannot exist thermodynamically. With lowering of the temperature during cooling, the spinel formed by dissociation oxidizes back to hematite and magnesioferrite.

Increased amount of $\mathrm{MgO}$ thermodynamically increases dissociation at a given temperature, and lowers the temperature to enter the spinel-one phase region where hematite cannot exist thermodynamically.

- In pellets with $3 \%$ olivine, mass loss due to dissociation commenced at $1190-1230^{\circ} \mathrm{C}$, earlier the finer the olivine. The mass loss of the sample with the finest olivine was about $10 \%$ of the total gain during oxidation at $1270^{\circ} \mathrm{C}$. The whole mass loss was regained during cooling.

\section{Acknowledge}

The funding from HLRC, LKAB and CAMM (Center of Advanced Mining and Metallurgy at Luleå University of Technology), Sweden is greatly acknowledged. The authors would like to express their gratitude for the late Anders Rutqvist for his valuable contribution to the present study.

\section{REFERENCES}

1) J. Sterneland: Ph.D. thesis, Royal Institute of Technology, (2002), https://www.lkab.com/sv/SysSiteAssets/dokument/kund/2002-someaspects-on-the-reduction.pdf, (accessed 2017-08-24).

2) G. H. Li, Z. K. Tang, Y. B. Zhang, Z. X. Cui and T. Jiang: Ironmaking Steelmaking, 37 (2010), 393.

3) X. Fan, M. Gan, T. Jiang, L. Yuan and X. Chen: J. Cent. South Univ. Technol., 17 (2010), 732.

4) M. Matsumura, T. Takayama, K. Hara, Y. Yamaguchi, O. Ishiyama, K. Higuchi, S. Nomura, T. Murakami, M. Hayashi and K. I. Ohno: Tetsu-to-Hagané, 103 (2017), 388.

5) R. A. Dave: Can. J. Chem. Eng., 74 (1996), 1004.

6) S. P. E. Forsmo, S.-E. Forsmo, P. Samskog and B. M. T. Björkman: Powder Technol., 183 (2008), 247.

7) D. Papanastassiou and G. Bitsianes: Metall. Trans., 4 (1973), 487.

8) M. Tang, H. J. Cho and P. C. Pistorius: Metall. Mater. Trans. B, 45 (2014), 1304.

9) H. J. Cho, M. Tang and P. C. Pistorius: Metall. Mater. Trans. B, 45 (2014), 1213.

10) H. J. Cho and P. C. Pistorius: Iron \& Steel Technology Conference and Exposition (AISTech) 2012 Proc., Association for Iron \& Steel Technology, Warrendale, PA, (2012), 503.

11) M. Hallin, D. Thulin and M. Tottie: 53rd Ironmaking Conf. Proc., Vol. 53, Iron and Steel Society, London, (1994), 287.

12) M. Brämming and J. Wikström: Scand. J. Metall., 31 (2002), 88.

13) B. Eriksson, J. Wilstrom and A. Ahnqvist: Scand. J. Metall., 13 (1984), 316

14) P. Semberg, A. Rutqvist, C. Andersson and B. Björkman: ISIJ Int., 51 (2011), 173.

15) P. Semberg, C. Andersson and B. Bjorkman: Miner. Metall. Process., 31 (2014), 126.

16) P. Semberg, C. Andersson and B. Björkman: ISIJ Int., 53 (2013), 391.

17) K. Lingtan, L. Yang and W. Lu: Scand. J. Metall., 4 (1983), 166.

18) L. Darken and R. Gurry: J. Am. Chem. Soc., 68 (1946), 798.

19) S. P. E. Forsmo, A. J. Apelqvist, B. M. T. Björkman and P. Samskog: Powder Technol., 169 (2006), 147.

20) H. M. Ahmed, A. Persson, L. S. Ökvist and B. Björkman: ISIJ Int., 55 (2015), 2082.

21) S. P. E. Forsmo: Int. J. Miner. Process., 75 (2005), 135.

22) V. Niiniskorpi: Proc. 60th Ironmaking Conf., Iron and Steel Society, London, (2001), 767.

23) V. Niiniskorpi: Ph.D. thesis, Åbo Akademi University, (2004), https://books.google.se/books/about/Development_of_Phases_ and_Structures_Dur.html?id=G5WaAAAACAAJ\& $\overline{\text { redir_esc }}=\bar{y}$, (accessed 2017-08-24).

24) P. Semberg, A. Rutqvist, C. Andersson and B. Björkman: Ironmaking Steelmaking, 38 (2011), 321.

25) U. Leimalm, L. S. Ökvist and B. Björkman: The 4th Int. Cong. on the Science and Technology of Ironmaking (ICSTI'06), The Iron and Steel Institute of Japan, Tokyo, (2006), 201.

26) C. W. Bale, E. Bélisle, P. Chartrand, S. A. Decterov, G. Eriksson, K. Hack, I. Jung, Y. Kang, J. Melançon, A. D. Pelton, C. Robelin and S. Petersen: Calphad, 33 (2009), 295.

27) I. Jung, S. A. Decterov and A. D. Pelton: J. Phys. Chem. Solids, 65 (2004), 1683. 